\title{
Genes, games and the sexes
}

Natural selection selects the fittest, but the fittest need not be selfish, according to two new books. Starting from different backgrounds, evolutionary biologist Joan Roughgarden and anthropologist and primatologist Sarah Blaffer Hrdy converge on that message regarding sex and reproduction.

The authors also converge on another point. Theorists go wrong less because of the assumptions they know they are making, and more because of the ones they don't. Roughgarden shows how modellers can agree about the maths and the results of particular models, yet, thanks to rival metaphysical assumptions, still disagree fiercely about the verbal narratives they attach to the models. For Blaffer Hrdy, the problem is simpler: it stems largely from the sex of the researchers. She is interested in primate, ape and human mothers. Early researchers were mostly men, but recently, large numbers of women scientists have been asking new questions and noticing different things.

The Genial Gene is the latest round in the debate between Roughgarden's social-selection theory and sexual-selection theory. Many have contributed to it, but I shall concentrate on Roughgarden's responses to her most thoughtful critic, zoologist Tim Clutton-Brock.

Roughgarden starts by differentiating sex from the terms male and female. Sex is the combining of gametes from two parents. The production of large gametes by females and small ones by males - anisogamy — is thought to be responsible for competition

The Genial Gene: Deconstructing
Darwinian Selfishness
by Joan Roughgarden
University of California Press: 2009 .
272 pp. $\$ 24.95, £ 14.95$
Mothers and Others: The Evolutionary
Origin of Mutual Understanding
by Sarah Blaffer Hrdy
Belknap/Harvard University Press:
2009. 432 pp. $\$ 29.95, € 19.95, € 21.00$

between the sexes. Since Angus Bateman's fly experiments, females have been portrayed as investing more in their gametes, and therefore being choosy about their mates. Males invest little in their gametes, mate with as many females as possible and compete with other males to do so. But Roughgarden proposes that anisogamy originally evolved to ensure contact between male and female gametes. Pursuing this to the genetic and cellular levels, she generates an alternative theory of reproduction.

Roughgarden's approach includes both developmental and evolutionary processes. She also explains reproductive behaviour as a process of bargaining and communication between the sexes, rather than competition. The two tiers break the genetic determinism implicit in single-tier evo-

lutionary models by granting more plasticity to individuals of both sexes when bargaining. The main innovation, however, concerns the bargaining process itself, and involves game theory.

Game theory traditionally analyses an interaction between two players; in this case, a male and a female. Mathematician John Nash developed its principal theorems in the 1950s, including the concept of Nash equilibria, whereby neither player in a game can do better by changing strategies. John Maynard-Smith introduced game theory to biology - by focusing on fitness pay-offs to interacting individuals in evolving populations, he attempted to capture what happens at both the individual and population levels.

Roughgarden complains that MaynardSmith introduced only the competitive half of game theory. She introduces the cooperative half, based on organisms communicating, bargaining and allocating side-payments to each other. Cooperation between the sexes leads to Nash bargaining solutions, not to Nash competitive equilibria. Different behavioural solutions at the developmental tier then translate into alternative evolutionary outcomes. As someone who works on the developmental process of niche construction, whereby the actions of organisms generate feedback in evolution by modifying natural selection pressures in environments, I like Roughgarden's two tiers.

That does not mean Roughgarden is correct,

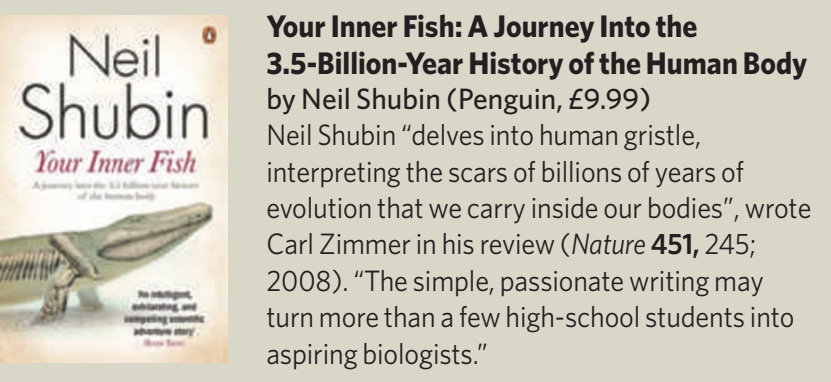

Your Inner Fish: A Journey Into the 3.5-Billion-Year History of the Human Body by Neil Shubin (Penguin, E9.99) Neil Shubin "delves into human gristle, interpreting the scars of billions of years of evolution that we carry inside our bodies", wrote Carl Zimmer in his review (Nature 451, 245; 2008). "The simple, passionate writing may turn more than a few

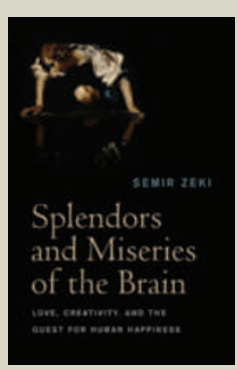

Splendors and Miseries of the Brain: Love, Creativity and the Quest for Human Happiness by Semir Zeki (Wiley-Blackwell, £16.99) Semir Zeki examines the brain's ability to seek knowledge and form concepts in creative areas such as music, art and literature. He gives us an insight into how the brain functions, what this means for happiness, and how even negative emotions can be a source of creativity. 
nor is sexual selection wrong. The awkward data for sexual-selection theory are not yet decisive. Also, as the mutual concessions and careful arguments between Clutton-Brock and Roughgarden show, there is often little empirical ground between them. Sexual selection starts with competition, but admits cooperation as a by-product. Social selection starts with mutual regard and cooperation, but admits competition when bargains break down. To compete, selfish genes must cooperate. To cooperate, genial genes must compete. It is difficult to sort between them. But Roughgarden succeeds in re-opening issues long thought closed.

Blaffer Hrdy's book is narrower in scope but also provocative. She argues that unlike other apes, Homo sapiens could never have evolved if human mothers had been required to raise their offspring on their own. Human infants are too helpless and too expensive in their demands for care and resources. So human females have to line up helpers - sometimes extending beyond their own kin - to raise their young. That requires both males and females to invest heavily in social skills for bargaining with other members of their groups. Blaffer Hrdy suggests that females in ancestral hunting and gathering groups may have thrived because they were free to be flexible in this way. Female flexibility was reduced when humans established settlements requiring male coalitions to defend them, probably leading to greater control of females by males.

More rides on these books than the relationship between the sexes. In her last chapter, Roughgarden distinguishes between Charles Darwin's repeatedly verified theory of "descent with modification", versus Herbert Spencer's unverified notion of the "survival of the fittest". It was Spencer who encouraged social Darwinism. Clearly we can go wrong if we attach faulty metaphors and narratives to evolutionary theory. The most refreshing aspect of both these books is the challenges they offer to what we thought we already knew.

John Odling-Smee is an emeritus fellow at Mansfield College, University of Oxford, Oxford OX13TF, UK.

e-mail: john.odling-smee@anthro.ox.ac.uk

\section{Managing nature as Earth warms}

Climate change is transforming the world as we know it. It disrupts biological clocks, pushes species to different latitudes and altitudes and shrinks biological diversity. It also challenges humanity to question its relationship with Earth; global warming is the antithesis of responsible stewardship. We look to science for guidance on how to turn back the hand of humankind, but it can provide only partial answers. Science is imperfect, unfeeling and slow compared with the steady rise of the global thermometer.

Into this mix of responsibilities, human identity and scientific uncertainty comes Anthony Barnosky's new book. Unlike other accounts of climate change, Heatstroke looks at the issue from the perspective of plants and animals. He introduces us to the Irish elk, the pack rat and biologists such as Jim Patton, a professor at the University of California, Berkeley - species and people that are helping to reveal the biotic signature of climate change.

Using many case studies, Barnosky explains how worldwide changes in climate are altering the reproductive rates, timing of breeding and living conditions of creatures. He is spot on in his description of new and exciting scientific findings, portraying them in an accessible and compelling way. Such findings include predictions of the existence of climates with no modern counterparts within 100 years, and a careful reconstruction of past climatic effects on small mammal communities. The reader becomes engulfed in a world of scientific discovery, searching through bones, walking transects to record the numbers of animal and plant species, and looking back across history to reveal the influence of climate on life.

This is not a happy book. Barnosky sounds the alarm about the biological effects of climate change, but his gloom and doom message could alienate readers. He repeatedly asserts that climate change will lead to permanent species loss: "At best, we seem to be witnessing wholesale changes in nearly every ecosystem on Earth. At worst, we may be witnessing the extinction of life as we've known it." The former statement is true, but the latter is extreme. In Yosemite and Yellowstone national parks in the United States, Barnosky reports changes in the composition and locations of species. But these places are not yet experiencing profound species loss. The public needs to understand how climate change is altering life on Earth and that such threats are very serious, but I worry that scientists risk a backlash if their primary message is the worstcase scenario.

Climate is a major determinant of where a species lives and how species interact. Biologists also know that climate change will outpace evolution for a great number of organisms, although perhaps not for bacteria, viruses and some insects. Barnosky describes the result as "like taking a color portrait and rendering it in black and white, or stripping all the harmonic notes out of a symphony". But not all organisms will be affected negatively; some will flourish. We need to figure out if climate change is eroding the species that humans value and replacing them with those that cause harm. And we must identify which species will be most affected, which ones will muddle through and which will rise to prominence. This information will help us to determine what sort of biotic world climate change is creating and what steps we might take to affect that change.

If we heed Barnosky's call to care about the impacts of climate change, we must reduce the greenhouse gases that we emit into the atmosphere and capture those already there. We could also help some species out.

Heatstroke describes the strategy of assisted migration - helping a species to relocate to a place where it might be expected to thrive.

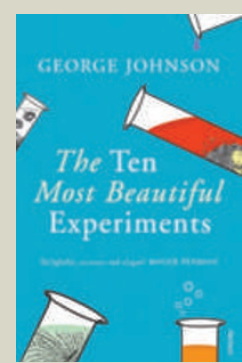

The Ten Most Beautiful Experiments

by George Johnson

(Vintage, $€ 8.99$ )

George Johnson's book covers ten of the most historically significant experiments in science including Isaac Newton's prisms and Ivan Pavlov's dogs. He does justice to each experiment, showing how ingenious and elegant it was - and how the process of experimenting may be as important as the conclusion.

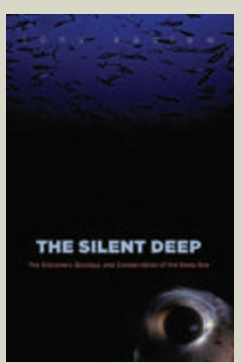

The Silent Deep: The Discovery, Ecology, and Conservation of the Deep Sea by Tony Koslow (Univ. Chicago Press, \$22.50)

Describing the huge variety of ocean life "with textbook depth on all aspects of deep-sea science and conservation," (Mark Schrope, Nature 447, 909-910; 2007), Tony Koslow examines how oceanography has developed and discusses human exploitation of the seas. 